\title{
SEROLOGICAL EVIDENCE OF CANDIDA INFECTION AFTER OPEN-HEART SURGERY
}

\author{
I. G. Murray, Helen R. Buckley* and G. C. Turner \\ Mycological Reference Laboratory, London School of Hygiene and \\ Tropical Medicine, and Liverpool Public Health Laboratory
}

CANDIDA endocarditis is a well-recognised complication of open-heart surgery (Jamshidi, Pope and Friedman, 1963; Climie and Rachmaninoff, 1965; McConnell and Roberts, 1967; Newsom, Lee and Rees, 1967; Conway et al., 1968), but its diagnosis presents difficulties. Even when infection is established, blood cultures may fail to yield candida. When, on the other hand, the diagnosis is in doubt, the isolation of Candida species may be of little significance without other evidence of infection, because of the frequency with which these organisms are found in mucocutaneous situations (Mackenzie, 1961; Marples, 1966) from which they may contaminate specimens. Clearly a reliable serological test would be of great value.

Winner (1955) concluded from a study of over 2500 subjects that a high agglutination titre was of little or no diagnostic significance in a case of suspected candida infection. However, Stallybrass (1964) and Taschdjian et al. (1964a and $b ; 1967)$ have produced evidence that precipitins to somatic antigens of Candida species seldom appear in the absence of infection. Our observations made on patients undergoing open-heart surgery suggest that the finding of high levels of precipitins to candida may be indicative either of candida endocarditis or inapparent candida infection.

\section{METHODS}

\section{Sera}

We have examined 409 sera for the presence of agglutinins and precipitins to Candida albicans, C. tropicalis, C. guilliermondii and C. parapsilosis. The study began when, between Nov. 1965 and May 1966, sera were received from four patients (M.B., C.B., J.C. and R.H.) in whom a clinical diagnosis of candida endocarditis had been made. When precipitins to Candida species were detected in them, the study was extended to another 64 patients who underwent open-heart surgery between June 1966 and Sept. 1967; two of these patients (D.S. and J.R.) developed candida endocarditis. As far as possible blood was taken immediately before operation and thereafter at weekly intervals. Agglutination and gel diffusion precipitin tests were carried out on all sera.

\section{Agglutination tests}

Agglutination tests were carried out with suspensions of whole yeast cells. Candida species were grown on glucose peptone agar for $48 \mathrm{hr}$ at $37^{\circ} \mathrm{C}$, washed off with isotonic saline and made into stock suspensions of approximately 50 per cent. packed-cell volume, which

Received 19 Feb. 1969; accepted 17 Apr. 1969.

* Present address: State of New York Department of Health, Albany, USA.

J. MED. MICROBIOL.-VOL. 2 (1969) 
were kept frozen. When required, the stock suspension was diluted in saline to 2 per cent. packed-cell volume by haematocrit estimation, formaldehyde was added to a concentration of 0.08 per cent. and the suspension allowed to stand overnight. The following day, the yeasts were centrifuged out, washed once and resuspended in saline to a concentration of 2 per cent. $(\mathrm{v} / \mathrm{v})$. Doubling dilutions of the sera from 1 in 4 were made in saline in $0 \cdot 6-\mathrm{ml}$ volumes and to each dilution was added $0.06 \mathrm{ml}$ of a 2 per cent. suspension of candida. The serum-yeast mixtures were incubated at $37^{\circ} \mathrm{C}$ for $3 \mathrm{hr}$ and then stored at $4^{\circ} \mathrm{C}$ overnight. Agglutination of the yeast cells was readily seen with oblique lighting against a black background.

\section{Precipitin tests}

Antigens for precipitin tests were prepared by one or other of two methods according to the availability of apparatus. Washed cells of $C$. albicans suspended in saline were forced through a hydraulic press (X-press, AB Biox, 25-ml model) and the other three species were disrupted overnight in a Mickle shaker. Suspended solids were removed by centrifugation and the liquid phases were freeze-dried. Working antigens were prepared by dissolving the dried material in a buffer at $p \mathrm{H} 8.6$ (boric acid $6.7 \mathrm{~g}$ and sodium borate decahydrate $13.4 \mathrm{~g}$ per litre of distilled water) to concentrations of about $50 \mathrm{mg}$ per $\mathrm{ml}$. The optimal concentration for precipitation was determined by testing each antigen against serum from a rabbit hyperimmunised with the homologous species of Candida; this was done to try to obviate variations between the batches of antigen. Trial batches of $C$. albicans antigen prepared by the Mickle shaker method gave much the same results in precipitin tests as those produced by the hydraulic press. Taschdjian et al. (1964a) used antigens prepared by a similar method but disintegrated the yeasts by ultrasonication. Stallybrass used a Mickle shaker.

Precipitin tests were carried out by double diffusion in agar buffered to $p \mathrm{H} 8.6$ with the same borax-boric acid buffer as was used as antigen solvent; $2 \cdot 5-\mathrm{ml}$ quantities of agar were poured into plastic petri plates $5 \mathrm{~cm}$ in diameter. A pattern of wells was cut in the agar; a central well was surrounded by six equally spaced peripheral wells; two adjacent peripheral wells had a diameter of $2 \mathrm{~mm}$ and the other wells had one of $6 \mathrm{~mm}$; the rims of the peripheral wells lay $5 \mathrm{~mm}$ from that of the central well. The patient's serum was placed in the central well and suitable positive control sera were placed in opposite peripheral 6-mm wells. Antigen from one Candida species was placed in an opposing pair of wells, which included a small $(2 \mathrm{~mm})$ and a large one $(6 \mathrm{~mm})$, and antigen from another species was placed in the remaining pair of wells, one large and one small. Thus, two plates were required to test a serum with four antigens. The diameters of the small and large antigen wells were chosen so as to give a volume ratio of about 1:10 because it was found in preliminary experiments that weakly reacting sera gave the best precipitation reactions with the smaller volume of antigen and stronger sera reacted better with the larger volume. The plates containing antigens and antisera were kept for 5 days at $26^{\circ} \mathrm{C}$ and then washed in four changes of saline over a period of $24 \mathrm{hr}$. The agar was then lifted out of the petri dishes, placed on $3 \times 1 \mathrm{in}$. $(7.5 \times 2.5 \mathrm{~cm})$ glass slides, trimmed to fit, covered with filter paper and dried at $37^{\circ} \mathrm{C}$. The dried slides were stained for $10 \mathrm{~min}$. in naphthalene black $(0.05 \mathrm{~g}$ dissolved in methanol $50 \mathrm{ml}$, distilled water $40 \mathrm{ml}$ and glacial acetic acid $10 \mathrm{ml}$ ) and then differentiated in the same methanol-water-acetic acid solvent.

\section{RESULTS}

The results of the precipitin tests, as shown in the table, placed the patients in three well-defined groups. (1) The precipitin test was negative with antigens of all four Candida species in 35 patients (21 male and 14 female). Agglutination titres greater than 16 were obtained with C. albicans in 27 of these patients but with C. parapsilosis in only one. Two of the patients died, both from causes not connected with candida infection. (2) The precipitin test was positive with antigen from only one species of Candida in 13 patients ( 8 male and 


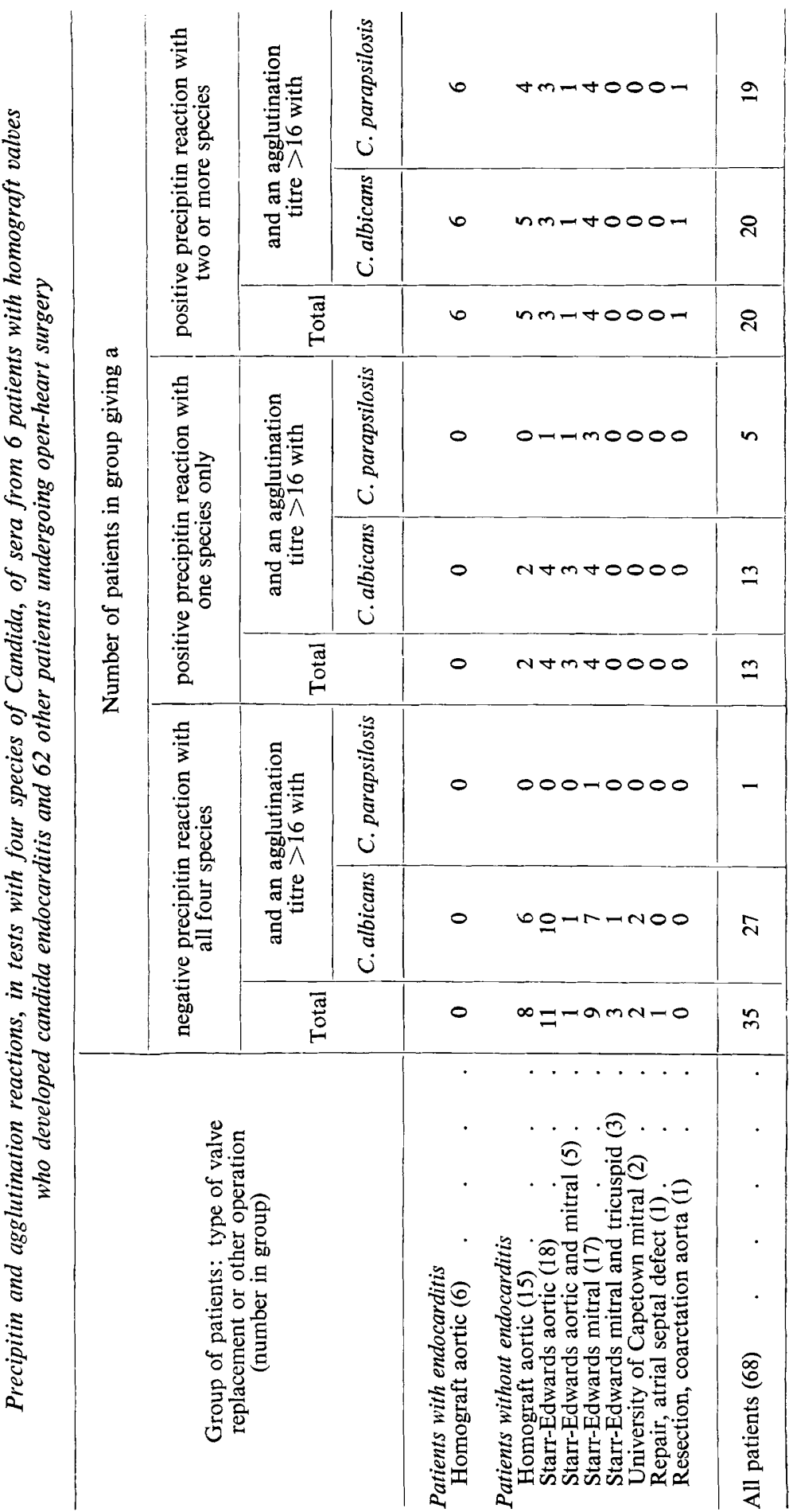


5 female). The positive precipitin result was obtained with C. albicans in 12 patients and with $C$. parapsilosis in one. Agglutination titres greater than 16 were obtained with $C$. albicans in all 13 patients but with $C$. parapsilosis in only five of them. One patient died from failure of Starr-Edwards valve suture; he was the one patient in whom the precipitin test was positive with $C$. parapsilosis. (3) The precipitin test was positive with at least two species of Candida in 20 patients ( 18 male and 2 female). All 20 patients gave precipitation with C. albicans and 16 of them did so with C. parapsilosis. Agglutination titres greater than 16 were obtained with $C$. albicans in all 20 patients and with C. parapsilosis in 19 of them. This group included all six patients with candida endocarditis, of whom five died (vide infra). Of the other 14 patients in the group, one died and the cause of death was multiple myocardial infarcts.

In all three groups, sera that agglutinated $C$. albicans to titres greater than 16 also agglutinated $C$. tropicalis and $C$. guilliermondii to similar levels. Of the 20 sera in the third group, 17 precipitated with $C$. tropicalis antigen and 8 with C. guilliermondii antigen.

\section{Findings in six patients with endocarditis}

Patients M.B., C.B. and J.C. The pathological findings in these three patients were reported by McConnell and Roberts. In all three, C. albicans was isolated from vegetations on the aortic valve cusps at necropsy. In M.B., blood culture $3 \mathrm{mth}$ after operation yielded C. albicans and, despite treatment with amphotericin B, he died 10 days later. Serum obtained at necropsy gave positive precipitin tests with $C$. albicans and $C$. tropicalis. In C.B., yeasts were seen in a large embolus removed from near the bifurcation of the aorta $2 \mathrm{mth}$ after operation and treatment with amphotericin B was begun. Specimens of serum obtained 2 wk later and at necropsy after 5 wk were precipitin-positive with all four species of Candida. In J.C., serum obtained $5 \mathrm{wk}$ after operation was precipitin-positive with $C$. albicans, C. tropicalis and C. parapsilosis. One week later, C. albicans was cultured from his urine, but he died soon afterwards despite treatment with amphotericin $\mathbf{B}$.

Patient D.S. A specimen of serum obtained 11 days after operation from this patient was precipitin-negative, but agglutinated $C$. parapsilosis at a dilution of 1 in 16 . Although he developed the infectious-mononucleosis-like illness known as post-cardiotomy syndrome (Wheeler, Turner and Scannell, 1962; Smith, 1964) and had a monocyte count of 7000 per $\mathrm{mm}^{3}$, subsequent sera were also precipitin-negative and the $C$. parapsilosis agglutinin titre fell to less than 4. After the patient had been discharged from hospital no serum was examined until his return to hospital $7 \mathrm{mth}$ later with suspected endocarditis; he then died suddenly as a result of a coronary embolus. At necropsy, C. parapsilosis was recovered from vegetations on the homograft valve. His serum was precipitin-positive and gave high agglutination titres with all four species of Candida.

Patient R.H. Specimens of serum obtained 4 and 8 wk after operation were precipitinpositive with all four specimens of Candida, but the patient remained well and 7 mth later his serum was precipitin-negative. Just over a year later when he was readmitted with a suspected embolus, his serum was strongly precipitin-positive and gave very high agglutination titres with all four species. Blood cultures yielded C. parapsilosis. Treatment was begun and subsequently the aortic valve homograft was removed and replaced by a Starr-Edwards prosthesis. C. parapsilosis was isolated from vegetations on the excised homograft valve. Subsequently the patient made a good recovery and over a period of $10 \mathrm{mth}$ there was a steady diminution in precipitin reactions and agglutinin titres. A year after the second valve operation, precipitins could be detected only by concentrating the serum, although agglutinins were still moderately elevated. Thereafter no further sera were examined for $10 \mathrm{mth}$ and this final specimen was completely negative by both precipitation and agglutination tests. 
Patient J.R. No specimen of serum was examined at the time of the original homograft operation, but when the patient was readmitted $18 \mathrm{mth}$ later with suspected endocarditis, precipitin and agglutinin tests were negative on two sera. Blood cultures yielded a streptococcus and he was given penicillin for $6 \mathrm{wk}$. His pyrexia returned, however, and blood cultures now yielded $C$. albicans; three sera obtained at weekly intervals were strongly positive with all four candidas by precipitation and agglutination. After treatment with amphotericin $B$ for 4 wk the homograft was replaced by a Starr-Edwards valve. He died $5 \mathrm{wk}$ after this operation and at necropsy the Starr-Edwards valve was enshrouded with a membrane from which a penicillin-resistant strain of Staphylococcus aureus was isolated. No candida was isolated or seen in sections although in sera obtained at weekly intervals after operation the precipitin reactions and agglutinin titres had not declined significantly.

\section{Times of appearance of precipitins and rise in agglutinin titres}

In 47 patients, at least one specimen of serum was obtained before operation and none of these specimens was precipitin-positive. After operation the precipitin test became positive with one species of Candida in 9 of the patients and with two or more species in 10 of them. In the majority, the positive reaction was first detected in the 2 nd wk after operation. The agglutination titre rose after operation in 36 patients. In only 4 patients was the rise detected in the serum taken during the 1st wk after operation. In 31 of them, however, there was a sharp rise in agglutinins in the serum between the 10th and 13th post-operative days. In one patient the rise was not observed till the 19th day. Appropriate investigations in these patients did not reveal any association between the appearance of candida antibodies and either the post-cardiotomy syndrome or heavy candida infection of mouth, throat or intestinal tract.

\section{Discussion}

The 68 patients from whom specimens of serum were obtained included six in whom candida infection of the aortic valve had become established. In two of them, after initial treatment with amphotericin B, the infected valve was successfully removed and replaced by a Starr-Edwards prosthesis. If this method of treatment is to succeed it is clear that diagnosis should be made as early as possible. In both the successfully treated patients an early indication of the nature of the infection was obtained by examining the serum for precipitins and agglutinins to four species of Candida. In these, as in the other four patients with candida endocarditis, we found precipitins to two or more species of Candida and relatively high titre of agglutinins to C. albicans and C. parapsilosis. The presence of antibodies to species of Candida other than the infecting organism is doubtless due to antigenic sharing among the species and to the fact that cross-reactions become more evident as the titre of antibodies rises.

An unexpected and unexplained finding was the appearance of high antibody titres in some patients who showed no sign of candida endocarditis. Chew and Theus (1967) and Pepys et al. (1968) detected precipitins to C. albicans group-A mannan in 48 and 23 per cent. of healthy subjects respectively. Other workers have, however, found precipitins only in patients with deep-seated candida infections and Pepys et al. suggest that these differences may be attributable 
to the use of antigens of different concentration and chemical composition. Pepys et al. noted that precipitins against mannan and, less frequently, precipitins against protein antigens of $C$. albicans, are common in asthma; these workers used purified mannan in low concentration as their precipitating antigen and found positive reactions in 4.5 per cent. of healthy subjects when unconcentrated serum was used. The antigens used in the present study contained little mannan. It is important to note that in our investigation, sera were obtained from 47 patients before operation and, by our methods, none of these sera was precipitin-positive.

The timing of the antibody response with the appearance of precipitins and the rise in agglutinin titre in the $2 \mathrm{nd}$ wk after operation suggests that infection began at about the time of operation. It is doubtful whether contaminated homograft valves can be incriminated as the source of the infection, since the antibody response often occurred after the insertion of a Starr-Edwards prosthesis. Such prostheses are also susceptible to candida infection (Watanakunakorn et al., 1968). During the period under review, antibiotic treatment was given for a few days during and after operation and there was no evidence that heavy proliferation of candida in the upper respiratory tract or alimentary tract was the cause of the antibody response. Other possible causes include undetected candidaemia or deep-seated transient infection in, for example, the lungs. It is clearly important to discover whether similar candida antibody reactions can be demonstrated after other types of surgery, including other forms of chest surgery.

Although precipitins to several species of Candida were present in all our patients with candida endocarditis, it is clear that this finding is not by itself diagnostic of that infection. Nevertheless, patients who develop this serological pattern shortly after heart valve surgery should be watched carefully for infective complications, and special attention should be paid to patients with homograft valve replacements since these replacements are peculiarly susceptible to candida infection.

\section{SUMMARY}

Six patients with homograft aortic valves who developed endocarditis due to infection with Candida albicans or $C$. parapsilosis were found to have serum precipitins and high titres of agglutinins to several species of Candida. In 14 of 62 other patients undergoing open-heart surgery, a similar serological pattern developed in the $2 \mathrm{nd}$ wk after operation, suggesting the possibility that otherwise undetected candida infection was present. A further 13 of the 62 patients developed antibodies to a single species of Candida. Such patients, especially those with homograft valve replacements, should clearly be watched carefully for infective complications.

We wish to thank Dr E. Mavis McConnell and Dr F. Whitwell for much valuable help and advice on histological aspects of this problem; the physicians and surgeons of the Liverpool Regional Cardiac Centre for the opportunity to investigate their patients; and the staffs of the pathology departments of Sefton General and Broadgreen Hospitals for numerous cultures and sera. 


\section{REFERENCES}

CHEW, W. H., AND TheUS, T. L. . . . 1967. J. Immun., 98, 220.

Climie, A. R. W., ANd Rachmaninoff, N. 1965. J. Thorac. Cardiovasc. Surg., 50, 431.

Conway, N., KothaRI, M. L., LoCKey, 1968. Thorax, 23, 353. EUNICE, AND YACOUB, M. H.

JAMShIDI, A., PoPe, R. H., AND Fried- 1963. Archs Intern. Med., 112, 370. MAN, N. H.

MCConnell, E. M., AND Roberts, C. . 1967. J. Clin. Path., 20, 555.

MACKENZIE, D. W. R. . . . . . . 1961. Sabouraudia, 1, 8.

Marples, Mary J. . . . . . . . . . . 1966. Proc. N.Z. Ecol. Soc., 13, 29.

Newsom, S. W. B., LeE, W. R., AND ReES, 1967. Br. Heart J., 29, 457. J. R.

Pepys, J., Faux, Jennifer A., Long- 1968. J. Allergy, 41, 305. BOTTOM, JoAN L., MCCARTHY, D. S., AND HaRgreave, F. E.

SMITH, D. R. . . . . . . . . 1964. Br. Med. J., 1, 945.

Stallybrass, F. C. . . . . . . . . 1964. J. Path. Bact., 87, 89.

Taschidian, Claire L., Dobkin, G. B., 1964a. Sabouraudia, 3, 129. Caroline, Leona, and Kozinn, P. J.

Taschdjan, Claire L., KozinN, P. J., 1964b. Ibid., 3, 312. and Caroline, Leona

Taschdjan, Claire L., Kozinn, P. J., 1967. J. Infect. Dis., 117, 180. OKas, A., Caroline, Leona, and Halle, M. A.

Watanakunakorn, C., Carleton, J., 1968. Archs Intern. Med., 121, 243. GOLDBERG, L. M., AND HAMBURGER, M.

Wheeler, E. O., Turner, J. D., AND 1962. New Engl.J. Med., 266, 454. SCANNELL, J. D.

WinNer, H. I. . . . . . . . . . 1955. J. Hyg., Camb., 53, 509. 